\title{
ALFABETIZAÇÃO CIENTÍFICA E DOMÍNIOS DO CONHECIMENTO CIENTÍFICO: PROPOSIÇÕES PARA UMA PERSPECTIVA FORMATIVA COMPROMETIDA COM A TRANSFORMAÇÃO SOCIAL
}

\author{
Maíra Batistoni e Silva ${ }^{1}$ \\ https://orcid.org/0000-0002-5490-1862
}

\author{
Lúcia Helena Sasseron² \\ https://orcid.org/0000-0001-5657-9590
}

\section{RESUMO:}

Desde meados do século passado, o campo da Educação em Ciências vem discutindo e incorporando novos propósitos à ideia de Alfabetização Científica (AC). No atual momento histórico, tem sido defendida uma perspectiva formativa para a AC comprometida com a transformação social. Considerando essa perspectiva, retomamos as ideias já consolidadas na literatura sobre os Eixos Estruturantes (EE) da $\mathrm{AC}$ e propomos sua releitura a partir de considerações sobre o ensino de ciências como prática social e sobre os domínios conceitual, epistêmico, material e social do conhecimento científico, com vistas à proposição de um referencial teórico para a área. $\mathrm{Na}$ perspectiva da $\mathrm{AC}$ apresentada, detectamos a complexidade do segundo EE, visto que ele congrega os diferentes domínios do conhecimento.

\section{ALFABETIZACIÓN CIENTÍFICA Y DOMINIOS DEL CONOCIMIENTO CIENTÍFICO: PROPOSICIONES PARA UNA PERSPECTIVA FORMATIVA COMPROMETIDA CON LA TRANSFORMACIÓN SOCIAL}

\section{RESUMEN:}

Desde mediados del siglo pasado, el campo de la Educación en Ciencias sigue discutiendo e incorporando nuevos propósitos a la idea de Alfabetización Científica (AC). En el momento histórico actual se ha defendido una perspectiva formativa para la AC comprometida con la transformación social. En esta perspectiva, retomamos las ideas ya establecidas en la literatura acerca de los Ejes Estructurantes (EE) de la AC y proponemos su relectura basada en las consideraciones acerca de la enseñanza de la ciencia como práctica social y sobre los dominios conceptual, epistémico, material y social del conocimiento científico, con el fin de proponer un marco teórico para el área. Desde la perspectiva de la AC presentada, detectamos la complejidad del segundo EE, ya que reúne los diferentes dominios del conocimiento.
Palavra-chave:

Ensino de Ciências;

Eixos Estruturantes;

Prática social.

Palabras clave: Enseñanza de la Ciencia; Ejes Estructurantes; Práctica social.

\footnotetext{
1 Universidade de São Paulo, Instituto de Biociências, São Paulo, SP, Brasil.

2 Universidade de São Paulo, Faculdade de Educação, São Paulo, SP, Brasil.
} 


\title{
SCIENTIFIC LITERACY AND DOMAINS OF SCIENTIFIC KNOWLEDGE: PROPOSITIONS FOR A FORMATIVE PERSPECTIVE COMMITTED TO SOCIAL TRANSFORMATION
}

\begin{abstract}
:
Since the 1950's, Science Education research area has been discussing and incorporating new purposes to Scientific Literacy (SL). Currently, a formative perspective has been proposed for SL committed to social transformation. From that, the ideas already consolidated in the literature on Structuring Axes (SA) were considered taking into account the domains of scientific knowledge: conceptual, epistemic, material and social. We understand that it could be a theoretical framework for Science Education. From the perspective of the SL presented, we detect the complexity of the second SA, as it encompasses the different domains of knowledge.
\end{abstract}

\author{
Keywords: \\ Science Teaching; \\ Structuring Axes; \\ Social practice.
}

\section{INTRODUÇÃO}

Ao ponderar sobre as reformas do ensino de ciências a partir da segunda metade do século passado, a professora Myriam Krasilchick avalia as tendências consolidadas por meio de elementos vinculados a políticas para a organização curricular, traçando também indicações a respeito do objetivo do ensino de ciências e da concepção de ciência circulante em cada momento retratado (Krasilchick, 2000). Na discussão ao longo do texto, ela expóe que entre os anos 1950 e 1970 o objetivo do ensino de ciências era formar a elite intelectual, tendo sido alterado para a intenção de formar o cidadão trabalhador, entre as décadas de 1970 e 1990 e, na sequência, a formação do cidadão-trabalhador-estudante. E qual seria o objetivo do ensino de ciências nos anos atuais?

Passadas duas décadas da publicação deste ensaio, para além da crise sanitária causada pela pandemia de Covid-19, estamos experimentando diferentes formas de violação de direitos humanos em um contexto global caracterizado por crises políticas e ambientais sintetizadas em desafios como mudanças climáticas, aumento das migrações e circulação massiva de desinformação, ampliada pelas tecnologias digitais.

Importante reconhecer que a sociedade contemporânea está imersa em abundantes trocas de informaçôes e marcada pela velocidade e extensão da propagação das notícias. Aliados a isso, cada vez de modo mais constante, redes sociais, arquivos de áudio e de vídeos expostos em plataformas apropriadas ou divulgados nessas redes e em aplicativos de mensagens instantâneas são a fonte por meio da qual grande parte da população procura informações sobre temas variados, inclusive aqueles relacionados à ciência e à tecnologia (Centro de Gestão e Estudos Estratégicos, 2019).

Neste cenário, vivenciamos um momento histórico de intensificação dos impactos ambientais e das injustiças sociais no qual a prerrogativa de quem anuncia ideias não se restringe a atores específicos e não passa por mecanismos de avaliação e controle já consolidados nas mídias tradicionais. Pontos de vista e propostas de conhecimento são expostos e apresentados ao público de modo amplo e irrestrito, sem qualquer compromisso com os fatos, e são rapidamente acessados e retransmitidos. Se, por um lado, o acesso a informaçóes por grande parte da população é algo a ser comemorado, considerando a possibilidade de justiça social pela divulgação ampla de conhecimento, por outro, a falta de clareza se há e quais são os critérios envolvidos para a avaliação das informações divulgadas é fator de preocupação, considerando a ação de movimentos negacionistas e conspiratórios que sustentam práticas sistemáticas de manipulação de dados e informaçôes com finalidades econômicas, políticas e ideológicas, relativizando as noções de verdade e objetividade e promovendo uma desconfiança generalizada sobre os fatos e um descrédito em relação à ciência (McIntyre, 2018; Levitin, 2019; Silva \& Videira, 2020). 
São muitas as hipóteses explicativas para o surgimento desses grupos e para a disseminação do descrédito em relação à ciência e aos cientistas (Small \& Malon, 2007) e as pesquisas indicam se tratar de um fenômeno complexo e multifatorial (Gauchat, 2008; Rutjens et al., 2018), exigindo, portanto, diferentes níveis de reação (Silva \& Videira, 2020). No âmbito da educação científica, defendemos a importância do reconhecimento do que é ciência, quais são as normas e valores que regem esta atividade e como elas são consideradas e utilizadas pelos membros das comunidades científicas. Portanto, expor o caráter social da atividade científica parece ser condição indispensável para a formação de sujeitos capazes de avaliar criticamente informações a respeito de sua realidade social e de transformá-la (Valladares, 2021, Alsop \& Benzce, 2014, Pedretti \& Nazir, 2011, Santos, 2008). Na literatura de Educação em Ciências (Duschl, 2008, Stroupe, 2015), estas ações têm sido pensadas por meio do ensino de ciências como prática social, ou seja, as situaçôes didáticas em que os estudantes se envolvem com conteúdos, práticas e processos da construção do conhecimento como modo de possibilitar a compreensão de que as ciências não são um empreendimento reservado a poucos sujeitos, mas uma atividade social alicerçada em interaçóes e em padrões públicos reconhecidos pela comunidade científica. Estes aspectos são apresentados também na literatura sob a perspectiva de um ensino que permita a alfabetização científica dos estudantes.

Neste artigo, a partir de discussóes sobre como o ensino de ciências tem sido abordado na área de pesquisa em Educação em Ciências, temos como propósito expor fundamentos teóricos e dialogar com eles para a argumentação a favor de uma perspectiva formativa de sujeitos que, ocorrendo em espaços educativos, oportunize condiçóes para a incorporação de modos de pensar, agir e tomar decisóes. De modo mais específico, propomos uma reflexão sobre o conceito de Alfabetização Científica como perspectiva formativa, retomando definiçóes e objetivos a ela associados, explorando relaçóes com a literatura sobre a aprendizagem das ciências como prática social e sobre os domínios do conhecimento científico, com vistas à proposição de um referencial teórico para a área.

Por se tratar de um artigo teórico, organizamos as discussões a partir da exposição de ideias originais presentes na literatura em Educação em Ciências, pela qual foi possível apontar premissas da área. Reconhecendo-as e relacionando-as às relaçóes por nós estabelecidas em pesquisas e vivências no ensino de ciências, apresentamos proposições fundantes para o desenvolvimento da alfabetização científica em situações de ensino nos dias atuais.

Antes de prosseguirmos, considerando a importância do termo para a discussão aqui apresentada, é importante pontuar que utilizaremos as iniciais em maiúsculas para nos referirmos ao conceito de Alfabetização Científica, e utilizaremos iniciais em minúsculas para apresentar o processo e o resultado de açóes educacionais que visem ao seu desenvolvimento. Deste modo esperamos tornar mais claras distinçóes entre a concepção de Alfabetização Científica e as discussóes teóricas que a envolvem e a concretização da alfabetização científica como consequência de ações didático-pedagógicas e de processos cognitivos.

\section{SOBRE A ALFABETIZAÇÃO CIENTÍFICA}

A ideia de Alfabetização Científica não é recente nas pesquisas da área de Educação em Ciências. Em artigo de 1998, Paul Hurd afirma ter sido o autor do primeiro artigo, publicado em 1958, em que scientific literacy é exposto como objetivo do ensino de ciências e traça um breve histórico de como ideias similares ao que hoje concebemos pela expressão scientific literacy surgiram em discussóes nos campos filosófico, social, político e educacional. Mas a ideia subjacente a esta expressão não surge apenas em literatura em língua inglesa. Publicações em língua francesa (Astolfi, 1995; Fourez, 1999, 1994) surgem como expressóes la culture scientifique e alphabétisation scientifique, em língua espanhola como alfabetización cientifica (Cajas, 2001; Díaz et al., 2003; Gil-Pérez \& Vilches-Peña, 2001; Membiela, 2007), em língua portuguesa, no Brasil é comum encontrarmos a adoção das expressões Alfabetização Científica, Letramento Científico e Enculturação Científica (Sasseron \& Carvalho, 2011), havendo ainda o uso de Literacia Científica nos trabalhos em português de pesquisadores portugueses (Carvalho, 2009; Mendes \& Reis, 2012; Vieira, 2007). 
No cenário nacional, entendemos que scientific literacy é expressão em disputa vinculada à adesão teórica e à tradução adotada (Cunha, 2018; Martins, 2011; Sasseron \& Carvalho, 2011). Associadas às ideias de scientific literacy, encontramos, nas produções brasileiras, o uso das expressóes Enculturação Científica, Letramento Científico, Alfabetização Científica e Alfabetização Científica e Tecnológica, havendo preponderância no uso das expressóes Letramento Científico e Alfabetização Científica.

A expressão Enculturação Científica sempre surge com a intenção de que os estudantes, em aulas de ciências, tenham a oportunidade de vivenciar aspectos da cultura científica (Mortimer, 1996, Vogt, 2006, Carvalho \& Tinoco, 2006, Carvalho, 2013). Apesar de sua baixa incidência, é possível encontrar marcas do processo de enculturação nas definições de Letramento Científico e de Alfabetização Científica quando estas revelam a intenção de que o ensino de ciências permita aos estudantes o contato com diferentes aspectos da investigação científica e não apenas com os conceitos, leis e teorias.

O Letramento Científico aparece em textos que destacam o caráter social da apropriação e uso dos conhecimentos das ciências e, em muitas publicações brasileiras, relaciona-se ao ensino com abordagem CTS, ou seja, às temáticas de sala de aula em que se pretende expor os estudantes à análise crítica de situaçóes em que fiquem evidentes as relaçóes e os conflitos entre ciência, tecnologia e sociedade (Mamede \& Zimmermann, 2007, Santos \& Mortimer, 2001). Identificamos relação entre a adoção dessa expressão e os estudos sobre o letramento em Língua Portuguesa realizados por Kleiman (1995) e Soares (1998), uma vez que ele é concebido como o aprendizado advindo de práticas sociais e não a apropriação mecânica de um código. Importante ressaltar que Soares (2004) discute as aproximações e os distanciamentos entre letramento e alfabetização e expõe o entendimento de que o surgimento do primeiro tema, no Brasil, tem relação com o fracasso de métodos e estratégias para a alfabetização dos estudantes. Assim, o letramento surge como uma alternativa para propor e avaliar ações e processos em que se almeja a formação de leitores e produtores de texto. Importando esta concepção para o objetivo do ensino de ciências, o Letramento Científico ocupa-se da tarefa de oferecer condiçóes para que os estudantes possam compreender e analisar fenômenos estudados pelas ciências e a vivência com artefatos e conhecimentos científicos. Além disso, entendemos haver uma forte tendência sustentada nos estudos sobre Letramento Científico em abordar os temas das ciências a partir da análise de situações em que estão explícitas as influências e inter-relações entre ciência e sociedade.

A Alfabetização Científica figura em muitos trabalhos de pesquisa da área de Educação em Ciências vinculada a objetivos formativos concebidos para as ações educacionais em que se pretende a formação dos estudantes para a compreensão de elementos da atividade científica e seu uso para análise de situaçóes e tomada de decisóes (Lorenzetti \& Delizoicov, 2001, Krasilchick \& Marandino, 2007; Sasseron \& Carvalho, 2011; Marques \& Marandino, 2018; Sasseron \& Silva, 2021). Há ainda pesquisadores brasileiros que adotam a expressão Alfabetização Científica e Tecnológica, seja pela tradução do termo utilizado por Fourez em sua célebre publicação de 1994 (Alphabétisation scientifique et technique: Essai sur les finalités de l'enseignement des sciences), ou pela filiação teórica ao enfoque CTS (ciência-tecnologia-sociedade) em uma perspectiva crítica destas interações e da dinâmica social a elas associadas (Richetti \& Milaré, 2021, Auler, 2003). A adoção da expressão Alfabetização Científica por pesquisadores da área (Lorenzetti \& Delizoicov, 2001, Sasseron \& Carvalho, 2011), sustenta-se no entendimento do processo de alfabetização como concebido por Paulo Freire (2014), ou seja, um processo que não se vincula apenas a ações dos sujeitos em decifrar e dominar códigos escritos, e que se concretiza por meio e a partir da autoformação manifestada como agência para análise de situaçóes e contextos. Ainda com base em Soares (2004), aprendemos que a ideia de alfabetização passou a ser criticada por estudiosos deste processo em Língua Portuguesa a partir da identificação do fracasso em seu estabelecimento entre os estudantes. Entendido como vinculado a métodos e estratégias de ensino, o fracasso da alfabetização passou a ser exposto na contraposição ao letramento, em que as abordagens de ensino traziam à tona elementos da realidade dos estudantes. Isso já estava previsto nas ideias de Paulo Freire sobre alfabetização. 
Sendo assim, entendemos que as divergências e aproximações entre letramento e alfabetização não são originárias nem pertencentes ao campo de pesquisa em Educação em Ciências. E, com base nos pressupostos de Freire, a Alfabetização Científica pode ser entendida como a formação do sujeito para compreensão dos conhecimentos, práticas e valores de uma área de conhecimento para análise de situações e tomada de decisóes em ocasióes diversas de sua vida. Esta compreensão congrega elementos já previstos nas ideias de enculturação e de letramento.

Reforçando que a adoção das expressões Letramento Científico ou Alfabetização Científica por diferentes pesquisadores pode ser entendida a partir das vinculaçóes teóricas por estes assumidas, parece-nos importante avaliar as atribuiçóes consideradas para formação dos sujeitos que se espera letrar ou alfabetizar cientificamente. Pelo exposto no parágrafo anterior, neste texto trabalhamos com a expressão Alfabetização Científica ao concebê-la como a perspectiva formativa em que os estudantes têm contato com elementos da cultura científica, podendo incorporar as normas e práticas sociais deste campo para uso em avaliação e tomada de decisões no seu cotidiano. A partir desta opção teórica, recorremos ao trabalho de Roberts (2011) e de Valladares (2021) em que os pesquisadores apresentam e caracterizam as concepçóes para Alfabetização Científica presentes na literatura da área de pesquisa em Educação em Ciências.

Em 2011, Roberts identificou duas visões recorrentes nos currículos para educação científica: A visão I, também considerada internalista, está atrelada a aspectos internos da atividade científica no sentido em que se preocupa em oferecer aos sujeitos, condiçôes e oportunidades para que percebam como a ciência se estrutura em termos de produtos e processos, bem como explicita atenção ao desenvolvimento de entendimento conceitual; já a visão II, considerada externalista, está voltada às relações que a ciência expressa, impóe e recebe da sociedade, compreendendo a ciência como empreendimento social e a importância do seu ensino para a tomada de decisões na vida cotidiana. Roberts (2011) ressalta que a principal diferença entre as duas visóes reside em seus propósitos formativos e não em detalhes sobre a definição de Alfabetização Científica. Ainda assim, compreendemos que o propósito formativo orienta a escolha dos conteúdos a serem trabalhados em situaçóes de ensino-aprendizagem, assim como as abordagens didáticas adotadas. Diante disso, entendemos que a visão I da AC envolve os elementos e as atividades tradicionalmente discutidos em sala de aula, enquanto a visão II expõe ações e relaçôes provenientes deste ensino na vida cotidiana dos sujeitos. Isto posto, a visão II considera que a formação escolar almeja não apenas a aprendizagem de elementos surgidos e debatidos naquele espaço, buscando fazer com que as discussóes e os modos de propor e avaliar ideias sejam extravasados para outros contextos, ou seja, para que a formação do sujeito não seja apenas para a escola, mas pela escola.

Recentemente, Valladares (2021) realizou uma análise das principais visões da Alfabetização Científica desenvolvidas nos últimos 20 anos e caracterizou o contexto histórico associado às visóes de $\mathrm{AC}$ organizadas anteriormente por Roberts (2011). Segundo a autora, as visóes I e II da AC resultam do desenvolvimento dos estudos em Ciência, Tecnologia e Sociedade (CTS) que enriqueceram o debate sobre os efeitos das atividades científicas e tecnológicas na sociedade e complexificaram as visóes da Alfabetização Científica. Para Valladares (2021), as visóes I e II da AC refletem, respectivamente, uma imagem positivista da ciência isolada da sociedade e uma ciência pós-positivista vinculada à sociedade.

Mais recentemente, os estudos CTS evidenciaram como a sociedade e a cultura são co-construídas pela ciência, essa nova concepção exigiu uma nova visão da Alfabetização Científica. Como resposta, inspirada nos trabalhos de Yore (2012), Liu (2013) e Santos (2008) que discutem novas perspectivas para a Alfabetização Científica, Valladares (2021) expandiu o escopo conceitual desenvolvido na visão II de Roberts (2011) e caracterizou uma visão III, na qual defende a importância da participação ativa em debates em torno da ciência e o engajamento em questôes sociocientíficas comprometido com valores como equidade e justiça social. Para a autora:

(...) esses aspectos tornam a visão III mais alinhada aos desafios do século XXI, porque para transformar as relaçôes humanas e consequentemente os diferentes sistemas de injustiça, lacunas econômicas, culturais e sociais, e para mudar as crescentes expressóes de ódio e violência contra certos grupos sociais, bem como para impedir a exacerbação da crise ambiental, não basta contextualizar a ciência e refletir sobre seus múlti- 
plos riscos e impactos, mas sim uma orientação diferente da educação científica, na qual com um conjunto de competências que promovem maior ativismo social e maior agência individual e coletiva é obrigatório (Valladares, 2021, p. 565, tradução nossa).

Concordamos com a visão de Alfabetização Científica de Valladares (2021), pois ela atualiza a ideia de AC necessária ao contexto do século XXI integrando construçôes teóricas já presentes nas visôes I e II de Roberts (2011) de modo coordenado e associado ao ativismo social. Dessa maneira, embora a mudança de propósito da Alfabetização Científica exija diferentes abordagens e estratégias didáticas, entendemos que a visão III de $\mathrm{AC}$ congrega e transcende conhecimentos que já eram defendidos nas visóes I e II anteriormente caracterizadas. A síntese dessa ideia está organizada na Figura 1.

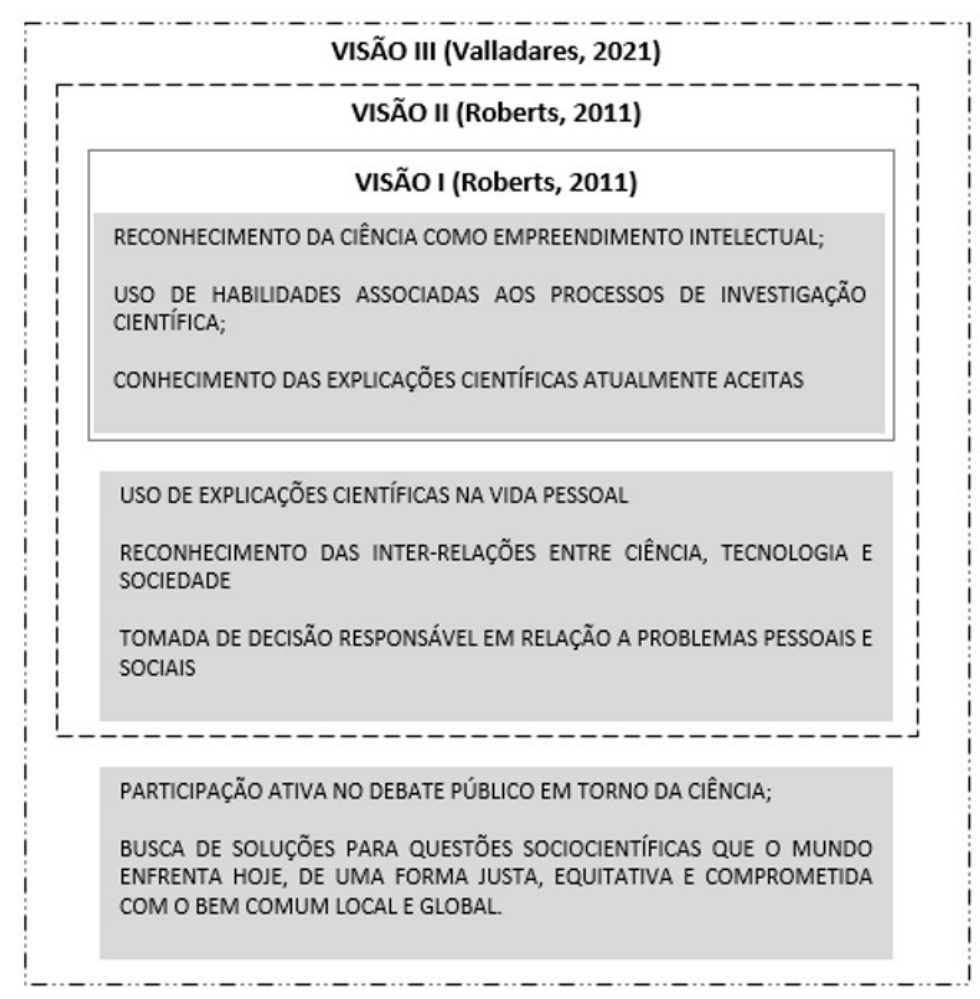

Figura 1. Conhecimentos e habilidades necessários às diferentes visões de Alfabetização Científica baseada em Roberts (2011) e Valladares (2020).

Essa figura sintetiza a primeira premissa deste trabalho: as relaçôes entre as diferentes visões de Alfabetização Científica como complementares e não excludentes. Da discussão sobre o conceito de AC, entendemos que desde meados do século passado, o campo da Educação em Ciências vem discutindo e incorporando novas perspectivas a esta ideia. A ideia de sua complementaridade pressupóe o entendimento de que não é possível alcançar uma AC comprometida com a transformação social, como proposto por Valladares (2021) sem, por exemplo, reconhecer a ciência como um empreendimento intelectual, como já era defendido na visão I, cujas propostas de conhecimento impóem e recebem influências da sociedade, como descrito na visão II. Neste sentido, não nos interessa discutir uma visão em contraposição a outras, mas assumir que, para o momento histórico presente, é urgente considerar uma perspectiva de Alfabetização Científica mais ampla e explicitamente voltada à transformação social. 


\section{SOBRE O ENSINO DE CIÊNCIAS E A APRENDIZAGEM DE CIÊNCIAS COM VISTAS À ALFABETIZAÇÃO CIENTÍFICA}

Diante do já exposto, assumimos que a efetivação da alfabetização científica é decorrente da perspectiva formativa em que os estudantes reconhecem as ciências naturais como área de conhecimento e, portanto, como empreendimento pautado em normas e práticas desenvolvidas e acordadas pelas comunidades científicas, gerando conhecimentos sobre seu objeto de estudo (o mundo natural), sendo influenciada por demandas advindas ou impostas pela sociedade, ao mesmo tempo que influencia comportamentos e modos. A alfabetização científica apenas se concretiza pelas intensas e delicadas simultaneidade e interveniências entre a abordagem de conceitos, de modos de construção de conhecimento e de formas de posicionamento e atuação em situações da vida em sociedade por meio e a partir de características da atividade científica.

Entendemos ser importante expor nossa compreensão de que a alfabetização científica não é a solução única e inequívoca para a formação de sujeitos que possam compreender a presença, as influências e as implicaçôes das ciências na sociedade. Apesar disso, e tendo isso como pressuposto, uma segunda premissa importante para a consolidação das ideias em discussão neste artigo é a da percepção de que as ciências naturais como tradicionalmente abordadas em sala de aula muito se diferem das ciências naturais entendida como uma forma de conbecimento bumano, marcada por ser uma prática social, em que normas e valores regem seu desenvolvimento (Knorr-Cetina, 1999; Longino, 1990; 2002; Pickering, 1995), em que se assume o caráter falível e transitório do conhecimento e o pensamento crítico para avaliação cética de informaçôes, hipóteses e dados (Pilati, 2018; Shermer, 2011), caracterizando a atividade científica como um empreendimento público que se desenvolve pela dialética e por meio de diálogos. As ciências naturais que aparecem como disciplina escolar tendem a ser apresentadas em discursos monológicos, excluindo os processos de investigação e de comunicação essenciais para o desenvolvimento das ideias, o que pode acarretar o apagamento de controvérsias e obstáculos e reforçar a ideia de que a atividade científica é um empreendimento privado.

Ao longo dos anos, muitos dos esforços para garantir a participação dos estudantes em aulas de ciências enfocaram o ensino por descoberta, com atividades fundamentadas em processos orientados para realização de tarefas, a realização de açóes experimentais com modo de favorecer a aprendizagem conceitual e, mais recentemente, a crítica como componente essencial para a prática em ciências e, consequentemente, do desenvolvimento de conhecimentos (Osborne, 2016). Estas mudanças de perspectiva são descritas como pertencentes a estruturas de ensino e aprendizagem das ciências pensadas historicamente como sendo a ciência como lógica, ciência como mudança conceitual e a ciência como acúmulo de conhecimento (Lehrer \& Schauble, 2006; Stroupe, 2014). Há, atualmente, um movimento propositivo do ensino de ciências como prática social (Jiménez-Aleixandre \& Crujeiras, 2017, Kelly \& Licona, 2018, Sasseron, 2021), ou seja, a abordagem das ciências que traga a possibilidade de que os estudantes vivenciem aspectos da atividade científica, realizando práticas para a investigação, a argumentação e a modelagem de problemas. Entende-se que, ao realizar estas práticas, os estudantes possam reconhecer as instâncias sociais para a produção e consolidação de conhecimento nas ciências (Duschl, 2008; Lehrer \& Schauble, 2006; Stroupe, 2014). Nesta perspectiva, o ensino de ciências afasta-se de concepções que se preocupam apenas com aspectos conceituais e epistêmicos, permitindo o reconhecimento de outras esferas que influenciam e condicionam a atividade científica.

Por ser muito comum a associação entre prática e atividade experimental, cabem aqui alguns apontamentos sobre o ensino de ciências como prática social, a fim de evitarmos tal associação imediata e equivocada.

Estudos de filosofia, sociologia e antropologia da ciência exploram exemplos de atividades científicas destacando o papel da comunidade de atores para a constituição de uma área de pesquisa e, na relação direta, pela constituição de normas, valores e práticas que regem a atividade (Knorr-Cetina, 2000; Longino, 1990; 2002; Pickering, 1995). Considerando que a "investigação científica é uma atividade humana colaborativa" (p. 17, tra- 
dução nossa), Longino (1990) descreve fatos e argumenta de modo circunstanciado pelo entendimento de que a atividade científica é uma prática humana e, portanto, social. Segundo esta pesquisadora, a objetividade da atividade científica é, inclusive, resultado de sua natureza social, pois é esta que garante a constituição de espaços e oportunidades para proposição de ideias e discussão de resultados, nos quais a crítica é aceita e esperada, acontecendo por meio de padróes compartilhados de conhecimentos, normas e valores. O processo de construção de conhecimento na ciência é, assim, reconhecido como processo desenvolvido pelas práticas da comunidade.

Deste modo, a concepção de ensino de ciências como prática social fundamenta-se na intenção de que aos estudantes sejam conferidas oportunidades para o reconhecimento das ciências como área de conhecimento da humanidade. E, ao assumir este compromisso, a vivência dos estudantes como prática da área torna-se uma demanda. Não é a tentativa de formar cientistas, embora esta possa ser uma consequência para alguns estudantes, mas a perspectiva formativa que almeja o acesso dos estudantes a uma nova cultura, a cultura científica. Por isso, retomando a concepção de Alfabetização Científica assumida, entendemos que a terceira premissa importante para estudo é o entendimento do ensino de ciências como prática social que pode consolidar-se quando aspectos internos e externos à ciência e as relações que ela tem com a formação cidadã dos sujeitos engajados em ações sociopolíticas são exploradas conjuntamente. Para se concretizar, na oposição a aulas estanques sobre conceitos aparentemente desconectados uns dos outros, o ensino de ciências como prática social demanda a seleção de temas de estudos das ciências em sua complexidade. Isso permite o contato dos estudantes com a diversidade de açôes necessárias de serem realizadas para a investigação, a identificação de que o estudo congrega conceitos e leis de um mesmo campo, solicita manejo de informaçóes e de materiais, mantém-se pelas interaçóes com ideias e conhecimentos e permite a proposição de inferências explicativas.

Além das açôes anteriormente descritas, a presença do ensino de ciências como prática social em sala de aula requer pautar o ensino em açóes didáticas para que os estudantes, pela vivência em processos de investigação, de argumentação e de modelagem de fenômenos e situações relacionados aos temas das Ciências Naturais, construam concepçóes sobre o que é a própria ciência e como suas práticas e valores podem ser transpostos para análise de outras situações do nosso cotidiano.

Estudando os diferentes modos como os sujeitos podem participar em atividades que sustentem e gerem aprendizagem, Lave e Wenger (1991) expõem a importância de que os processos cognitivos relacionem-se às práticas sociais como condição para a aprendizagem. Para eles, "a aprendizagem é um aspecto central e inseparável da prática social” (p. 31, tradução nossa). Esta caracterização assegura a consideração do engajamento como elemento importante para o processo de aprendizagem e, como consequência, a legitimação na participação como forma de pertencimento a um dado grupo social. Nesta perspectiva, a aprendizagem exige participação do sujeito no grupo e é promovida pelas interações no grupo, estando estas sujeitas ao reconhecimento e à atenção a normas, valores e práticas ali existentes.

Importante também expor que, para Wenger (2016), a prática não é o simples ato de fazer algo, mas de realizar algo em "contexto social e histórico que provê estrutura e entendimento ao que fazemos. Neste sentido, prática é sempre prática social” (p. 47, tradução nossa).

Assim reconhecida, a prática realizada em situaçôes educacionais ou em situações cotidianas está alocada em contexto social e, por isso, imersa em e sujeita aos elementos que sustentam a cultura e as práticas sociais de um determinado grupo. Por características como a destacada, a prática social dialoga de modo intenso com as instâncias que marcam as interações dos sujeitos e entre eles ao abrigar e congregar direitos e deveres destes para a vida em sociedade. É, pois, uma perspectiva fundamentada na compreensão da educação para a busca de soluçóes para os problemas enfrentados pelos sujeitos e grupos e, portanto, associada à alfabetização científica comprometida com a transformação social, tal como definida por Valladares (2021).

Estamos cientes de que efetivar o ensino de ciências como prática social em sala de aula exige considerar desafios e obstáculos de diferentes perspectivas que englobam a cultura escolar, e os modos próprios 
de organizar o ensino e subsidiar a aprendizagem, as questôes curriculares, que regulam as interaçóes didáticas, e os objetivos oficialmente expostos para a educação e aqueles socialmente construídos, abarcando não apenas a formação dos estudantes, mas também o êxito para a continuidade dos estudos. Como não temos o objetivo, neste artigo, de debater de que modo o ensino de ciências como prática deve ser considerado no planejamento didático, apenas reconhecemos esses desafios, pois sua discussão foge do escopo presente.

$\mathrm{Na}$ discussão teórica que aqui expomos, é importante frisar que o desenvolvimento da prática social e da visão III da Alfabetização Científica não é processo automático. Decorrente da prática social, o desenvolvimento da alfabetização científica em qualquer visão, é resultado de intencionalidade didática. A alfabetização científica depende, portanto, de açôes didáticas planejadas e implementadas com esta finalidade. Isso pode parecer óbvio, mas é necessário insistir neste aspecto como forma de reconhecer a importância de professores e educadores na formação dos sujeitos. Materiais didáticos, estratégias de ensino, formas de interações são todos elementos que se unem para a realização da atividade educativa e, sozinhos, não são capazes ou suficientes para o desenvolvimento da alfabetização científica sem que haja o esforço para expor modalidades de ações e de pensamento científicos tornando-os parte integrante e inseparável da prática educativa.

\section{ALFABETIZAÇÃO CIENTÍFICA: A MOBILIZAÇÃO DOS DOMÍNIOS DO CONHECIMENTO CIENTÍFICO PARA A TRANSFORMAÇÃO SOCIAL}

Tomados como prática social, o ensino e a aprendizagem das ciências concretizam-se a partir da abordagem dos domínios do conhecimento científico. Para esta discussão, recorremos a dois autores que abordam os domínios do conhecimento científico, Duschl (2008) e Stroupe (2015). Duschl (2008) elabora uma síntese das pesquisas das últimas décadas em três campos de investigação relevantes para o ensino de ciências (ciências da aprendizagem, estudos sobre as ciências, e a pesquisa em educação científica) para defender a incorporação, de forma integrada e equilibrada, de três domínios do conhecimento científico. O primeiro deles é o já bem estabelecido domínio conceitual, referente às "estruturas conceituais e aos processos cognitivos usados ao raciocinar cientificamente" (Duschl, 2008, p. 277, tradução nossa), ou seja, envolve o corpo de conhecimento produzido pela comunidade (conceitos, princípios, leis, teorias) usado para pensar na e sobre ciência (Stroupe, 2015). O segundo é o domínio epistêmico, relativo às "estruturas epistêmicas usadas no desenvolvimento e avaliação do científico conhecimento” (Duschl, 2008, p. 277, tradução nossa), em outras palavras, refere-se aos critérios e às normas segundo as quais os cientistas decidem o que sabem e porque sabem o que sabem. Já o terceiro é o domínio social, referente aos "processos sociais e contextos que moldam a forma como o conhecimento é comunicado, representado, argumentado e debatido” (Duschl, 2008, p. 277, tradução nossa), ou seja, o modo como os cientistas produzem, coletivamente, conhecimento objetivo, válido e confiável (domínio social). Para Stroupe (2015), a prática científica inclui, além dos três domínios descritos, o domínio material, que engloba o modo como os atores criam, adaptam e usam ferramentas, tecnologias, inscriçóes e outros recursos para apoiar o trabalho científico.

Assim, a primeira proposição deste texto é a consideração que, em situações didáticas, o desenvolvimento da alfabetização científica para a transformação social exige a mobilização dos quatro domínios do conhecimento de modo integrado a fim de concretizar práticas próprias das ciências em situaçôes de ensino como meio e forma para a consolidação dos propósitos formativos.

Em recente trabalho, Franco e Munford (2020) analisaram uma sala de aula de ciências e demonstraram como os três domínios do conhecimento descritos por Duschl (2008) podem ser mobilizados, de forma articulada, nas práticas discursivas da professora e dos estudantes. Os autores concluíram que a turma investigada usou conhecimentos do domínio conceitual para se engajar em práticas dos domínios epistêmico e social, assim como utilizou de práticas do domínio epistêmico e social para construir conhecimentos relacionados ao domínio conceitual. Outra conclusão derivada deste trabalho é a articulação entre os domínios 
epistêmico e social como primordial para a abordagem didática analisada, o ensino por investigação (Franco \& Munford, 2020), indicando que por meio das práticas sociais os domínios podem ser incorporados de modo articulado no ensino de ciências.

Deste modo, defendemos que o conhecimento do domínio conceitual não deve ser transformado em enunciados a serem memorizados, ou o domínio material em técnicas a serem aplicadas de maneira irrefletida tampouco os domínios epistêmico e social, em regras a serem seguidas. Para exemplificar como os domínios poderiam estar presente em uma situação de sala de aula, podemos imaginar uma atividade na qual os estudantes elaboram hipóteses sobre a relação entre duas variáveis relacionadas a um fenômeno e, em seguida, coletam dados empíricos necessários e adequados. Nesta situação, o domínio conceitual é repertório necessário para a elaboração das hipóteses, a opção pelas estratégias de investigação e a análise dos dados coletados, ao mesmo tempo em que pode ser reelaborado a partir das práticas que ocorrem ao longo da atividade. $\mathrm{O}$ domínio epistêmico refere-se ao conjunto de conhecimentos que sustenta as decisões sobre o modo de conduzir a coleta e a análise dos dados. O domínio material está relacionado aos tipos de instrumentos utilizados para coleta e a análise, desde os artefatos até os construtos para organização de informações e resultados. Já o domínio social envolve as formas de construção coletiva do conhecimento (seja ele conceitual, epistêmico ou material), por meio das quais os estudantes tornam suas ideias públicas, respondem uns aos outros (e não somente à professora), discordam, fazem perguntas relacionadas às discordâncias e levam em consideração as contribuições dos colegas para construir suas próprias ideias. Assim, adotando o ensino de ciências como prática social, entendemos que a articulação do domínio social com os domínios conceitual, epistêmico e material é primordial e qualifica como estes estarão presentes na sala de aula.

Apesar das pesquisas indicarem a importância das abordagens didáticas no ensino de ciências oferecer oportunidades para os estudantes vivenciarem as práticas sociais de construção do conhecimento, os currículos da disciplina escolar "Ciências Naturais" costumeiramente enfatizam o legado conceitual da área (Ko \& Krist, 2019). Ainda que os processos internos de produção do conhecimento conceitual sejam abordados, isso ocorre costumeiramente de modo desconectado da realidade e as vivências dos estudantes e sem compromisso com uma agenda emancipatória alinhada a valores como equidade e justiça social. Assim, as práticas didáticas mais frequentes no ensino de ciências revelam-se ainda mais atreladas à visão I de $\mathrm{AC}$, tal como caracterizada por Roberts (2011) e tornam-se insuficientes para alcançar a AC comprometida com a transformação social caracterizada por Valladares (2021).

Nossa concepção é que, embora estejam situados em uma dimensão interna à Ciência, a compreensão dos quatro domínios do conhecimento pelos estudantes é necessária e se articula a aspectos das visóes II e III de AC, tais como o uso cotidiano de explicaçóes científicas para lidar com eventos de sua vida pessoal, o reconhecimento de que as estruturas culturais e conceituais influenciam os cientistas e a si, o reconhecimento das inter-relações entre a atividade científica, o desenvolvimento tecnológico e suas implicações sociais, a análise e tomada de decisão em situações diversas de sua vida cotidiana e o engajamento sociopolítico com vistas à transformação socioambiental. Assim, por meio de uma perspectiva didática que integre os quatro domínios, o ensino de ciências pode possibilitar a formação de estudantes na direção de uma visão III de AC, tal como conceituada por Valladares (2021).

Importa explicitar que esta concepção não assume que, ao abordar os quatro domínios do conhecimento científico o desenvolvimento da visão III de AC se dá de maneira inequívoca e natural. Defendemos que há um conjunto de conhecimentos, capacidades e atitudes que ultrapassa os domínios do conhecimento científico e que, articulado à dimensão internalista, também deve ser contemplado no ensino de ciências com vistas à promoção da AC. São exemplos destes a defesa da humanidade, a valorização do diálogo como forma de resolução de conflitos, o respeito pelas diferenças, a busca pelo bem-estar dos indivíduos e das comunidades, da transformação pessoal e da mudança social (Teixeira et al., 2019). No entanto, a articulação do domínio social com os domínios conceitual, epistêmico e material, não apenas qualifica como estes estarão 
presentes na sala de aula, como também possibilita a articulação aos conhecimentos, competências e atitudes que ultrapassam os limites da Ciência.

Considerando o contexto do planejamento didático escolar, essa proposição não define conteúdos tampouco uma abordagem didática, mas fundamenta uma perspectiva formativa que deve orientar a construção de currículos e a escolha de diferentes abordagens didáticas de forma ampla, considerando todo o período de formação dos estudantes. Neste sentido, não consideramos que todos os domínios, assim como os conhecimentos relacionados ao ativismo em busca de equidade e justiça social, devam se apresentar em toda e qualquer abordagem didática de conteúdos e temas de ciências. É possível que sejam mais explícitos em algumas temáticas e menos em outras.

Para finalizar este tópico do texto, frisamos o reconhecimento de que a visão III de AC, tal qual proposta por Valadares (2021), possui propósitos distintos daqueles expressos pelas visóes I e II de AC trazidas por Roberts (2011), embora incorpore conhecimentos e habilidades listados pelas visóes que a precederam.

\section{ORGANIZANDO AS DIMENSÕES DA ALFABETIZAÇÃO CIENTÍFICA}

Nos itens anteriores, evidenciamos que a concepção de Alfabetização Científica assumida por nós não é unidimensional, ou seja, envolve conhecimentos de diferentes naturezas assim como valores e formas de agir e, por isso, a qualificamos como multidimensional, o que vem sendo pautado desde revisóes bibliográficas seminais, como as de Miller (1983) e Fourez (1994) e permanece vigente em trabalhos da última década que se propuseram a discutir a definição do termo Alfabetização Científica, como Bybee (2016) e Choi et al. (2011).

No Brasil, Sasseron e Carvalho (2008) analisaram relevantes trabalhos sobre AC com o intuito de discutir o conceito e seus objetivos e, ao fim, propuseram os chamados Eixos Estruturantes da Alfabetização Científica, os quais sintetizam as habilidades elencadas por diferentes pesquisadores preocupados com o desenvolvimento da alfabetização científica e dialogavam com a ideia de multidimensionalidade, visto que representam diferentes elementos contidos na ideia de AC.

Tal como propostos pelas autoras, os Eixos Estruturantes da Alfabetização Científica são: ${ }^{1}$ (i) a compreensão básica de termos, conbecimentos e conceitos científicos fundamentais, concerne na possibilidade de trabalhar com os alunos a construção de conhecimentos científicos necessários para que seja possível a eles aplicá-los em situaçôes diversas e de modo apropriado em seu dia a dia, ou seja, relacionada ao desenvolvimento da dimensão conceitual dos conhecimentos das ciências; (ii) a compreensão da natureza das ciências e dos fatores éticos e politicos que circundam sua prática, vinculada às possibilidades de reconhecimento das ciências como um campo em constantes transformações, cujas atividades fundamentam-se em processos de aquisição e análise de dados, síntese e decodificação de resultados e permitindo aos sujeitos a percepção de que as construçôes científicas são fruto de atividade social; e (iii) o entendimento das relaçôes existentes entre ciência, tecnologia, sociedade e ambiente, refere-se à consideração de que a solução imediata para um problema em uma destas áreas pode representar, mais tarde, o aparecimento de um outro problema associado, ou seja, associado às influências mútuas entre estas esferas. Assim, este Eixo denota a necessidade de se compreender as aplicaçóes dos saberes construídos pelas ciências considerando as açóes que podem ser desencadeadas pela utilização dos mesmos.

Embora a multidimensionalidade seja constante na literatura sobre AC, ela vem se modificando historicamente de acordo com a agenda para o ensino de ciências e perspectivas formativas. Os três Eixos Estruturantes da AC (Sasseron \& Carvalho, 2008) podem ser considerados como marcos para o planejamento curricular e didático com vistas à promoção da alfabetização científica no Brasil. No entanto, cabe destacar que foram propostos há mais de uma década e, ainda que eles se alinhem à concepção de multidimensionalidade e às principais ideias sobre o desenvolvimento da alfabetização científica, no momento histórico em 
que foram elaborados, predominava na área da educação em ciências, a visão II de AC. Com a ampliação da visão de $\mathrm{AC}$ necessária para o século XXI, o desenvolvimento da concepção de aprendizagem de ciências como prática social e com a incorporação dos quatro domínios do conhecimento científico no debate sobre o ensino de ciências, defendemos a relevância de revisitá-los e analisá-los sob a ótica desses novos referenciais a fim de que possamos promover uma educação científica adequada para a resolução dos problemas que afetam nossa sociedade no tempo presente. Amplamente enfatizado em documentos curriculares, em materiais didáticos e em planejamentos de aula, o Eixo Estruturante da AC que trata da compreensão básica de termos, conhecimentos e conceitos científicos fundamentais alinha-se fortemente ao domínio conceitual do conhecimento científico. Por meio deste Eixo Estruturante são abordados alguns dos elementos da visão I, qual seja, a concretização de entendimentos sobre os fenômenos naturais e o aumento da complexidade destes. Pode-se ainda reconhecer elementos da visão II se os conceitos desenvolvidos são compreendidos pelos estudantes permitindo a eles a comparação e contraposição destas ideias com outras, apresentadas em sua vivência, que não dialogam com, ou mesmo negam, a ciência.

Em propostas de ensino tidas como mais tradicionais, porque se preocupam fortemente com a aprendizagem conceitual, este Eixo Estruturante costuma ser o mais abordado, senão exclusivamente trabalhado. Nestas ocasióes, o discurso de autoridade (Mortimer \& Scott, 2002) tende a ser a marca das interaçốes entre professores e estudantes, evidenciando mais uma vez a concepção de que os conceitos são a caracterização das ciências e, por isso, o foco central do ensino. Açôes didáticas voltadas apenas para este Eixo Estruturante podem resultar em aprendizagens sobre os principais temas e produtos das ciências naturais, mas na perspectiva do desenvolvimento da visão III de $\mathrm{AC}$, mostram-se insuficientes se o domínio conceitual não estiver integrado aos domínios epistêmico, material e social do conhecimento científico. Aqui é importante ressaltar que não defendemos o abandono ou mesmo a desvalorização do domínio conceitual nas abordagens didáticas, visto que eles são estruturantes para a compreensão da disciplina (ver Carvalho et al. (2020) para o caso da biologia), mas sim a sua articulação com os demais domínios outrora negligenciados.

O segundo Eixo Estruturante da Alfabetização Científica é apresentado como a compreensão da natureza das ciências e dos fatores éticos e políticos que circundam sua prática. Esse Eixo tem sido desenvolvido, por exemplo, por meio de situaçóes didáticas que retratam episódios históricos, retratando os muitos elementos que interferem e contribuem para a atividade científica, ou a partir de atividades planejadas para o desenvolvimento de práticas científicas pelos estudantes, como a argumentação, a investigação e a modelagem. Ainda que estas atividades possam ocorrer de modo tradicional (como exposto na discussão do Eixo Estruturante anterior), sua abordagem apenas ilustrativa e expositiva é incoerente à sua própria definição e sustentação das ideias.

Importante destacar que muitas vezes a adoção de atividades experimentais é tomada como a solução direta para o desenvolvimento pleno do segundo Eixo. Isso pode evidenciar a percepção pouco acurada do que envolve os processos de construção de conhecimento nas ciências (Erduran \& Dagher, 2014) como também a compreensão ingênua de que a manipulação de objetos e de aparatos experimentais é suficiente para o reconhecimento das ações, práticas e contextos que envolvem a produção de conhecimento.

Assim, é importante ressaltar que o desenvolvimento dos aspectos que compóem o segundo Eixo Estruturante da Alfabetização Científica não deve ser confundido com o trabalho experimental e apenas com ele. É preciso considerar como ele está sendo proposto e desenvolvido, ou seja, pelo trabalho experimental é possível que os estudantes entrem em contato com nuances características da construção de conhecimento nas ciências? É possível que eles compreendam como contextos social, histórico e cultural, impactam na proposição de novos estudos e na construção de novos entendimentos? É possível que os estudantes compreendam o diálogo entre construções teóricas e empíricas no fazer científico? Há possibilidade para ajustes e revisões dos modelos explicativos?

Considerando o que é apresentado por este Eixo Estruturante, entendemos ser possível estabelecer relações diretas com o domínio social do conhecimento científico, pois a "compreensão da natureza das 
ciências e dos fatores éticos e políticos que circundam sua prática” dialoga com o reconhecimento de normas, práticas e valores da atividade científica e, portanto, com elementos próprios da dimensão social. Também entendemos que, em situaçóes de sala de aula, ao fazer uso de artefatos existentes, adaptando-os para a situação em investigação ou desenvolvendo novas técnicas para o trabalho manipulativo ou intelectual, o domínio material do conhecimento científico pode ser mobilizado. Adicionalmente, a consideração da abordagem das temáticas por meio dos processos que caracterizam elementos sociais da atividade científica, ou seja, processos de investigação, argumentação e modelagem, confere situaçôes por meio das quais o domínio epistêmico esteja em curso, pelos movimentos contínuos de construção e de avaliação de planos para análise e de consolidação de ideias explicativas sobre fenômenos e situações em discussão. Neste sentido, ainda que não representativo deste Eixo Estruturante, as práticas de educação científica não podem prescindir do domínio conceitual e, assim, este se apresenta de forma articulada aos modos de participação e às práticas científicas que caracterizam este segundo Eixo Estruturante. Estamos cientes de que transformar práticas e planejamentos didáticos para mobilizar os domínios social, material e epistêmico do conhecimento científico na relação com os Eixos Estruturantes da AC não é tarefa simples. Não é escopo deste artigo discutir como isso pode se concretizar em sala de aula, mas entendemos que implica e demanda reconhecimento, pelos professores, de que a atividade científica é complexa, envolvendo, dentre outros, movimentos de investigação, argumentação e modelagem e se concretiza como trabalho social colaborativo.

As ideias correlatas a este segundo Eixo Estruturante já estiveram presentes nas visões I e II de AC: na visão I revela-se pela compreensão do desenvolvimento de processos e ferramentas próprias para a atividade científica, na visão II, pela possibilidade de que os estudantes, ao compreenderem modos e práticas características das ciências naturais que sustentam a forma de construir entendimento do mundo natural, utilizem destas estruturas e modos de pensar para entender contextos próximos e explicar situações vivenciadas. Considerando a visão III defendida neste trabalho, este Eixo também possibilita que os estudantes, munidos desse entendimento, participem de debates públicos em torno da ciência e atuem em prol de uma sociedade mais equitativa e justa.

Diante do exposto, aqui é importante explicitar a segunda proposição deste trabalho, que se refere à densidade e complexidade do segundo Eixo Estruturante da AC, visto que nele localizamos os elementos do domínio epistêmico, relativos aos critérios e às normas que regem as práticas de produção, comunicação e avaliação do conhecimento científico, do domínio material, pela demanda de uso, adaptação e construção de ferramentas manipulativas e intelectuais para o desenvolvimento de uma investigação e os elementos do domínio social, relativos às formas de construção coletiva do conhecimento, conhecimento este que pode ser conceitual, epistêmico ou material. Assim, ao defendermos, tal como Duschl (2008) e Stroupe (2015) a incorporação, de forma integrada e equilibrada, dos quatro domínios do conhecimento científico como condição para alcançarmos a perspectiva formativa da $\mathrm{AC}$, um olhar cuidadoso deve ser dado ao seu segundo Eixo, visto que este incorpora três domínios do conhecimento científico que não podem ser negligenciados na consolidação do ensino de ciências como prática social. Além disso, explicita-se a sua importância para articulação entre os domínios do conhecimento científico e o conjunto de conhecimentos e competências que ultrapassam os limites da Ciência e são necessários ao desenvolvimento da $\mathrm{AC}$ comprometida com a transformação social.

O terceiro Eixo Estruturante da AC é descrito como o "entendimento das relaçôes existentes entre ciência, tecnologia, sociedade e ambiente" e expóe a necessidade de que estas relaçóes, e as influências delas advindas e por elas sofridas, sejam abordadas em sua complexidade. Mais uma vez, entendemos ser possível sua abordagem em uma perspectiva tradicional de ensino, pela apresentação de quais são estas relaçóes a partir de exemplos históricos e contemporâneos. Contudo, assim realizada, pode estabelecer relaçóes apenas com o domínio conceitual, pela informação fornecida sobre as relaçóes entre a ciência, a tecnologia, a sociedade e o ambiente, não permitindo o desenvolvimento de elementos do domínio epistêmico e social e, portanto, desvalorizando a possibilidade de que os estudantes analisem contextos e situaçóes e, com isso, construam posicionamentos que venham a fomentar tomadas de decisão. Entendemos apenas ser possível o desenvolvimento desses aspec- 
tos, caso a abordagem do Eixo Estruturante ocorra pelo desenvolvimento dos domínios social e epistêmico do conhecimento científico. Do contrário, estas relaçôes serão explicitadas apenas como fato ou conhecimento já estabelecido, constituindo-se como conteúdo a ser declarado e dialogando com uma perspectiva tradicional do domínio conceitual, e pouco contribuindo para o desenvolvimento da alfabetização científica cidadã.

Tal como enunciado por Sasseron e Carvalho (2008), o terceiro Eixo da AC pode ser relacionado aos elementos da visão II de AC (Roberts, 2011) pois se remete ao reconhecimento das inter-relações entre ciência, tecnologia, sociedade e ambiente e à tomada de decisão responsável em situações da vida cotidiana. Recorrendo à proposição de Valladares (2011), e ao trabalho de Santos (2008), reconhecemos que o terceiro Eixo não explicita o engajamento sociopolítico voltado à participação ativa no debate público em torno da ciência e à busca por soluçóes justas, equitativas e comprometidas com o bem comum para questóes sociocientíficas. No entanto, ao pensarmos no ensino de ciências como prática, trazemos para as situações educacionais o contexto social dos sujeitos que dela participam e dialogamos com ele, possibilitando a mobilização das normas, práticas e valores que compóem a atividade científica de maneira articulada ao ativismo que se faz necessário à transformação socioambiental.

\section{CONSIDERAÇÕES FINAIS}

No início deste artigo, enunciamos o propósito de expor fundamentos teóricos com vistas à promoção da alfabetização científica como perspectiva formativa. Para tanto, dialogamos com algumas proposiçóes da área de pesquisa em Educação em Ciências a fim de elaborarmos uma definição de Alfabetização Científica relacionada à concepção de ensino e de aprendizagem das ciências como prática social e aos domínios do conhecimento científico em sala de aula.

Ao longo do texto, nossa argumentação, sustentada em fundamentos teóricos da Educação em Ciências (Duschl, 2008; Santos, 2008; Sasseron \& Carvalho, 2011; Stroupe, 2014; Valladares, 2021) e dos estudos em filosofia e sociologia da ciências (Longino, 1990; 2000; Pickering, 1995; Knorr-Cetina, 1999, Pilati, 2018), expôs premissas assumidas e proposiçóes construídas como forma de apresentar contribuiçóes para analisar, em uma perspectiva atual, necessidades e condicionantes para a efetivação da alfabetização científica.

A primeira premissa exposta surge da análise da Alfabetização Científica e nossa constatação de que existe coexistência e complementaridade entre as diferentes visões de $\mathrm{AC}$ presentes na literatura. Importante destacar a dimensão histórica na evolução dessas concepções que, embora existente, não acarreta a existência de uma dada visão em oposição a outras atualmente. Ainda assim, defendemos que o momento contemporâneo exige considerar a AC para a transformação social, como proposto por Valladares (2021), pela qual pode ser possível a formação de sujeitos que compreendam as ciências como mais um ator que, infelizmente, contribui para a consolidação de injustiças sociais e, por isso, tem papel na busca pela justiça. Não se trata de um movimento simples tampouco veloz, mas de um movimento urgente. A pandemia de covid- 19 escancara exemplos que referendam a urgência, desde as condições necessárias ou oferecidas para o distanciamento social e a prevenção ao contágio do novo coronavírus até a real e assustadora desigualdade no acesso a vacinas entre países ricos e pobres. A contribuição do ensino de ciências para esta situação, como mencionado, não é direta e imediata, mas pode ocorrer no futuro caso já se construam açôes para a vivência pelos estudantes de análise de situações em que se torne evidente o papel das ciências nestas discussões complexas e como, ao indivíduo, é possível buscar informações e auxílio para a transformação de seu contexto.

A segunda premissa exposta relaciona-se diretamente à anterior: a perspectiva formativa da AC para a transformação social exige o reconhecimento das ciências naturais como um campo de estudos da humanidade. Suas propostas de conhecimento podem trazer respostas para problemas sobre fenômenos do mundo natural, mas estas ciências não são as únicas formas de conhecimento responsáveis pelas e consideradas nas tomadas de decisóes. Para isso, é preciso reconhecer o escopo das ciências naturais na relação intrínseca com 
seus modos de propor, avaliar e referendar conhecimentos, ou seja, o reconhecimento das ciências como uma prática humana colaborativa, "organizada socialmente em modos que afetam tanto os objetivos quanto os critérios de sucesso” (Longino, 1990, p. 17, tradução nossa).

Relacionada a esta segunda, uma terceira premissa é importante para este estudo: a compreensão do ensino de ciências como prática social pelo qual os estudantes possam ter contato com diferentes aspectos da atividade científica. Assumi-la, traz ao debate a posição de que não são apenas conteúdos de sala de aula os conceitos e os modos de fazer das ciências, mas também outras características que circunscrevem a atividade científica como prática humana e, portanto, social. Assim, as ciências surgem como atividade ancorada em valores, normas e açôes construídas pela comunidade e identificadas como necessárias e legítimas para sua prática.

Como o próprio nome representa, as premissas não são nossas construções, mas constataçóes advindas do estudo da literatura da área. Elas são essenciais para as proposições apresentadas ao longo do texto. A primeira proposição expressa-se pelo entendimento de que o desenvolvimento da alfabetização científica para a transformação social exige a consideração dos domínios do conhecimento científico no planejamento e nas interaçốes didáticas. Entendemos não haver possibilidade de efetivação da alfabetização científica para a transformação social se os domínios do conhecimento não são explorados, e sua mobilização deve ser compreendida como açôes didáticas que trazem para a sala de aula as nuances e as características da atividade científica.

A segunda proposiçãa construída neste estudo refere-se à compreensão aprofundada sobre o segundo Eixo Estruturante da AC, que se torna possível atualmente devido ao desenvolvimento da pesquisa em Educação em Ciências. Proposto inicialmente como o Eixo Estruturante que traz à sala de aula a possibilidade de que os estudantes reconheçam a natureza das ciências e os fatores que influenciam sua prática (Sasseron \& Carvalho, 2011), considerando a concepção de AC para a transformação social (Valladares, 2021) e os domínios do conhecimento científico (Duschl, 2008; Stroupe, 2014) como elementos importantes para sua efetivação, este Eixo torna-se multifacetado e, por isso, complexo. Sua abordagem alinha-se à mobilização de aspectos epistêmicos, sociais e materiais das ciências, permitindo, por isso, o reconhecimento de elementos concernentes e influentes na atividade científica.

Neste sentido, entendemos que o presente trabalho traz contribuições para a área de pesquisa em Educação em Ciências, pois explora a AC como perspectiva formativa a partir de atualização e estabelecimento de relaçôes entre ideias já expressas na literatura, e porque articula dois relevantes referenciais teóricos adotados em estudos desta área, os domínios do conhecimento científico (Duschl, 2008; Stroupe, 2015), os Eixos Estruturantes da AC (Sasseron \& Carvalho, 2008) e as visóes de AC (Roberts, 2011; Valladares, 2021). Futuras pesquisas podem se preocupar em validar as articulações aqui propostas utilizando dados empíricos para a investigação do desenvolvimento da $\mathrm{AC}$ em diferentes abordagens e contextos didáticos.

Expostas as proposiçôes que sustentam nossa argumentação neste artigo, é importante afirmar nossa ciência de que elas não são simples dispositivos teóricos, uma vez que podem contribuir para a organização de currículos e planejamentos didáticos. Mas não é escopo deste texto aprofundar nestas discussóes de modo a propor alternativas curriculares e planos de ensino.

A partir de todo o exposto, estabelecemos aqui que a concepção de Alfabetização Científica discutida neste trabalho dialoga intrinsecamente com o conceito de alfabetização de Paulo Freire. Neste processo, segundo Freire (2014), o sujeito passa por uma autoformação, incorporando práticas de uma nova cultura que permitem sua atuação e intervenção sobre seu contexto. A concepção de Alfabetização Científica exposta ao longo deste estudo expóe ideias para concretizar a incorporação pelo sujeito de aspectos internos e externos à atividade científica, ou seja, os conhecimentos, as tecnologias, os modos de pensar e planejar investigaçóes e as relaçôes com a sociedade, na relação direta com seu engajamento sociopolítico. 


\section{AGRADECIMENTOS}

A primeira autora agradece ao $\mathrm{CNPq}$ pelo financiamento obtido por meio de auxílio à pesquisa processo $\mathrm{n}$. 441128/2019-0. A segunda autora agradece ao CNPq pelos financiamentos obtidos por meio do projeto Universal processo n. 428268/2018-8 e da bolsa Produtividade em Pesquisa processo n. 309928/2019-2.

\section{REFERÊNCIAS}

ALSOP, S., \& BENCZE, L. (2014). Activism! Toward a More Radical Science and Technology Education. In: J. BENCZE, S. ALSOP (ed.) Activist Science and Technology Education. Cultural Studies of Science Education (1-19) Springer, Dordrecht

ASTOLFI, J. P. (1995). Quelle Formation Scientifique pour l'École Primaire?, Didaskalia, 7, 105-112.

AULER, D. (2003). Alfabetização Científico-Tecnológica: um novo paradigma?, Ensaio Pesquisa em Educação em Ciências, 5(1), 68-83. https://doi.org/10.1590/1983-21172003050107

BYBEE, R. (2016). Scientific literacy. In R. GUNSTONE (Ed.). Encyclopedia of science education. (pp. 944-946). Springer.

CAJAS, F. (2001). Alfabetización Científica y Tecnológica: La Transposición Didactica Del Conocimiento Tecnológico, Enseñanza de las Ciencias, 19(2), 243-254. Disponível em: https://core.ac.uk/download/pdf/13268023.pdf

CARVALHO, G. S. (2009). Literacia científica: conceitos e dimensóes. In F. AZEVEDO \& M. G. SARDINHA (Org.). Modelos e práticas em literacia (pp.179-194). Lisboa, Portugal: Lidel.

CARVALHO, A. M. P., \& TINOCO, S. C. (2006). O Ensino de Ciências como 'enculturação'. In D. B. CATANI \& P. P. VICENTINI (Org.). Formação e autoformaçãao: saberes e práticas nas experiências dos professores. (pp. 251-255) São Paulo, SP/Brasil: Escrituras.

CARVALHO, A. M. P. (2013). Habilidades de Professores Para Promover a Enculturação Científica. Revista Contexto छ̊ Educação, 22(77), 25-49. https://doi.org/10.21527/2179-1309.2007.77.25-49

CARVALHO, I. N., EL-HANI, C. N., \& NUNES-NETO, N. (2020). How should we select conceptual content for biology high school curricula? Science $\sigma^{2}$ Education, 29, 513-547. https://doi.org/10.1007/s11191-020-00115-9

CENTRO De Gestão e estudos estratéGICOS (2019). Percep̧ão pública da Cछ̊T no Brasil, 2019. Resumo executivo. Brasília, DF/Brasil.

CHOI, K., LEE, H., SHIN, N., KIM, S., \& KRAJCIK, J. (2011). Re-conceptualization of scientific literacy in South Korea for the 21st century.Journal of Research in Science Teaching, 48(6), 670-697. https://doi.org/10.1002/tea.20424

CUNHA, R. B. (2018). O que significa alfabetização ou letramento para os pesquisadores da educação científica e qual o impacto desses conceitos no ensino de ciências. Ciência e Educação (UNESP), 24(1), 27-41. https://doi. org/10.1590/1516-731320180010003

DÍAZ, J. A. A., ALONSO, A. V., \& MAS, M. A. M. (2003). Papel de la Educación CTS en una Alfabetización Científica y Tecnológica para todas las Personas. Revista Electrónica de Enseñanza de las Ciencias, 2(2) 80-111. Disponível em http://reec.uvigo.es/volumenes/volumen2/REEC_2_2_1.pdf

DUSCHL, R. A. (2008). Science education in three-part harmony: balancing conceptual, epistemic and social learning goals. Review of Research in Education, 32(1), 268-291. https://doi.org/10.3102/0091732X07309371

ERDURAN, S., \& DAGHER, Z. R. (2014). Reconceptualizing the Nature of Science for Science Education Scientific Knowledge, Practices and Other Family Categories. Springer Netherlands.

FOUREZ, G. (1994). Alphabétisation Scientifique et Technique - Essai sur les finalités de l'enseignement des sciences. Bruxelas: DeBoeck-Wesmael. 
FOUREZ, G. (1999). L'enseignement des Sciences en Crise, 110, 96-99.

FRANCO, L. G., \& MUNFORD, D. O Ensino de Ciências por Investigação em Construção: Possibilidades de Articulaçôes entre os Domínios Conceitual, Epistêmico e Social do Conhecimento Científico em Sala de Aula. Revista Brasileira De Pesquisa Em Educą̧ão Em Ciências, 20(u), 687-719. https://doi.org/10.28976/19842686rbpec2020u6877192020

FREIRE, P. (2014). Educação e Mudança, São Paulo: Paz e Terra.

GAUCHAT, G. W. (2008). A Test of Three Theories of Anti-Science Attitudes. Sociological Focus, 41(4), 337-357. https://doi.org/10.1080/00380237.2008.10571338

GIL-PÉREZ, D., \& VILCHES-PEÑA, A. (2001). Una Alfabetización Científica para el Siglo XXI: Obstáculos y Propuestas de Actuación. Investigación en la Escuela, 43(1), 27-37. Disponível em: https://idus.us.es/ handle/11441/60304

HURD, P. (1998), Scientific Literacy: New Minds for a Changing World. Science Education, 82(3), 407-416. https:// doi.org/10.1002/(SICI)1098-237X(199806)82:3<407::AID-SCE6>3.0.CO;2-G

JIMÉNEZ-ALEIXANDRE, M.P., \& CRUJEIRAS, B. Epistemic Practices and Scientific Practices in Science Education. In: K. TABER \& B. AKPAN (Ed.). Science Education: An International Course Companion, p.69-80, Rotterdam: Sense Publishers. DOI:10.1007/978-94-6300-749-8_5. 2017.

KELLY, G. J., \& LICONA, P. Epistemic Practices and Science Education. In: M. MATTHEWS (ed.). History, Philosophy and Science Teaching, p. 139-165, Springer. DOI https://doi. org/10.1007/978-3-319-62616-1. 2018.

KLEIMAN, A. B. (1995). Modelos de Letramento e as Práticas de Alfabetização na Escola, In: A. B. KLEIMAN (org.), Os Significados do Letramento - Uma nova perspectiva sobre a prática social da escrita, Campinas: Mercado das Letras.

KNORR-CETINA, K. (1999). Epistemic cultures: How the sciences make knowledge. Cambridge, MA: Harvard University Press.

KO, M. L. M., \& KRIST, C. (2019). Opening up curricula to redistribute epistemic agency: A framework for supporting science teaching. Science Education, 103(4), 1-32. https://doi.org/10.1002/sce.21511

KRASILCHICK, M. (2000). Reformas e realidade: o caso do ensino das ciências. Perspectiva, 14(1), 85-93. DOI: http://dx.doi.org/10.1590/S0102-88392000000100010.

KRASILCHICK, M., \& MARANDINO, M. (2007). Ensino de Ciênciase Cidadania. 2a ed. São Paulo: Editora Moderna.

LAVE, J., \& WENGER, E. (1991). Situated learning: legitimate peripheral participation. New York: Cambridge University Press.

LEHRER, R., \& SCHAUBLE, L. (2006). Cultivating Model-Based Reasoning in Science Education. In R. K. SAWYER (Ed.). The Cambridge Handbook of the Learning Sciences (p. 371-387). Cambridge, MA: Cambridge University Press.

LEVITIN, D. (2019). O guia contra mentiras: como pensar criticamente na era da pós-verdade. Rio de Janeiro: Objetiva.

LIU, X. (2013). Expanding notions of scientific literacy: a reconceptualization of aims of science education in the knowledge society. In N. MANSOUR \& R. WEGERIF (Ed.). Science education for diversity: Theory and Practice (pp.23-39). Netherlands: Springer Netherlands.

LONGINO, H. E. (1990). Science as social knowledge: Values and objectivity in science inquiry. Princeton, NJ: Princeton University Press.

LONGINO, H. E. (2002). The fate of knowledge. Princeton, NJ: Princeton University Press.

LORENZETTI, L., \& DELIZOICOV, D. (2001). Alfabetização científica no contexto das séries iniciais. Ensaio Pesquisa em Educação em Ciências, 3(1), 37-50. https://doi.org/10.1590/1983-21172001030104 
MAMEDE, M., \& ZIMMERMANN, E. (2007). Letramento Cientifico e CTS na Formação de Professores para o Ensino de Física, trabalho apresentado no XVI SNEF - Simpósio Nacional de Ensino de Física, São Luís.

MARQUES, A. C. T. \& MARANDINO, M. (2018). Alfabetização científica, criança e espaços de educação não formal: diálogos possíveis. Educação e Pesquisa, 44(e170831), 1-19. https://doi.org/10.1590/s1678-4634201712170831

MARTINS, I. (2011). Literacy as metaphor and perspective in science education. In C. LiINDER, L. OSTMAN, D. ROBERTS, P. O. WICKMAN, G. D. ERICKSON, \& A. MCKINNON (Org.). Exploring the Landscape of Scientific Literacy (pp.90-105). New York/ USA: Routledge/Taylor and Francis.

MCINTYRE, L. (2018). Post-Truth. Cambridge, MA: MIT Press.

MILlER, J. D. (1983). Scientific Literacy: A Conceptual and Empirical Review. Daedalus, 112(2), 29-48. http:// www.jstor.org/stable/20024852

MEMBIELA,P.(2007).SobreLaDeseableRelaciónentreComprensiónPúblicadeLaCiênciayAlfabetizaciónCientífica. Tecné, Episteme y Didaxis, 22(u), 107-111. Disponível em: https://www.redalyc.org/pdf/6142/614265308007.pdf

MENDES, J., \& REIS, P. (2012). A promoção da Literacia científica no ensino da Física e da Química através da realização de uma atividade de investigação. Nuances: estudos sobre Educação, 22(23), 16-36. http://dx.doi. org/10.14572/nuances.v22i23.1748

MONTERIA, S. F. \& JIMÉNEZ-ALEIXANDRE, M. P. (2016). The practice of using evidence in kindergarten: The role of purposeful observation. Journal of Research in Science Teaching, 53(8): 1232-1258. https://doi.org/10.1002/tea.21259

MORTIMER, E. F. (1996). Construtivismo, Mudança Conceitual e Ensino de Ciências: Para Onde Vamos?. Investigações em Ensino de Ciências, 1(1), 20-39. Disponível em: https://www.if.ufrgs.br/cref/ojs/index.php/ienci/ article/view/645/436

PEDRETTI, E., \& NAZIR, J. (2011). Currents in STSE education: Mapping a complex field, 40 years on. Science Education, 95(4), 601-626. https://doi.org/10.1002/sce.20435

PILATI, R. (2018). Ciência e pseudociência: Porque acreditamos naquilo que queremos acreditar. 1a ed. São Paulo: Contexto.

PICKERING, A. (1995). The mangle of practice: Time, agency and science. University of Chicago Press, Chicago.

RICHETTI, G. P., \& MILARÉ, T. (2021). O Óleo no Nordeste Brasileiro: Aspectos da (an)alfabetização Científica e Tecnológica. Revista Brasileira De Pesquisa Em Educação Em Ciências, e29065, 1-. https://doi.org/10.28976/19842686rbpec2021u11871215

ROBERTS, D. (2011). Competing Visions of Scientific Literacy: The Influence of a Science Curriculum Policy Image. In C. LINDER, L. OSTMAN, D. ROBERTS, P. O. WICKMANN, G. D. ERICKSON, \& A. MCKINNON (Org.). Exploring the Landscape of Scientific Literacy (pp.11-27). New York/ USA: Routledge/Taylor and Francis.

RUTJENS, B. T., SUTTON, R. M., \& VAN DER LEE, R. (2018). Not All Skepticism Is Equal: Exploring the Ideological Antecedents of Science Acceptance and Rejection. Personality and Social Psychology Bulletin, 44(3), 384405. https://doi.org/10.1177/0146167217741314

SANTOS, W. (2008). Scientific literacy: a Freirean perspective as a radical view of humanistic science education. Science Education, 93(2), 361-382. https://doi.org/10.1002/sce.20301

SANTOS, W., \& MORTIMER, E. (2001). Tomada de Decisão para Ação Social Responsável no Ensino de Ciências. Ciência $\Xi^{2}$ Educação, 7(1), 95-111. https://doi.org/10.1590/S1516-73132001000100007

SASSERON, L. H., \& CARVALHO, A. M. P. (2008). Almejando a alfabetização científica no ensino fundamental: a proposição e a procura de indicadores do processo. Investigaçôes em Ensino de Ciências, 13(3), 333-352. Disponível em: https://www.if.ufrgs.br/cref/ojs/index.php/ienci/article/view/445

SASSERON, L. H., \& CARVALHO, A. M. P. (2011). Alfabetização Científica: uma revisão bibliográfica. Investigações em Ensino de Ciências, 16(1), 59-77. Disponível em: https://www.if.ufrgs.br/cref/ojs/index.php/ienci/article/view/246 
SASSERON, L. H., \& SILVA, M. B. (2021). Sobre Alfabetização Científica e sobre práticas epistêmicas: encontros de ações para a pesquisa e o ensino de ciências. In T. MILARÉ, G. P. RICHETTI, L. LORENZETTI, \& J. P. ALVESFILHO (Org.). Alfabetização Científica e Tecnológica na Educação em Ciências. (133-146). São Paulo: Livraria da Física.

SASSERON, L.H. (2021). Práticas constituintes de investigação planejada por estudantes em aula de ciências: análise de uma situação. Ensaio Pesquisa em Educação em Ciências, 23, 1-18. https://doi.org/10.1590/1983-21172021230101

SHERMER, M. (2011). Por que as Pessoas Acreditam em Coisas Estranhas. Pseudociência, Superstição e Outras Confusóes dos Nossos Tempos. São Paulo, SP/Brasil: Editora JSN.

SILVA, V. C., \& VIDEIRA, A. A. P. (2020). Como as ciências morrem? Os ataques ao conhecimento na era da pós-verdade. Caderno Brasileiro de Ensino de Física, 37(3), 1041-1073. https://doi.org/10.5007/21757941.2020v37n3p1041

SMALL, B., \& MALLON, M. (2007). Science, Society, Ethics, and Trust: Scientists' Reflections on the Commercialization and Democratization of Science. International Studies of Management Ev Organization, 37(1), 103-124. https://doi.org/10.2753/IMO0020-8825370105

SOARES, M. (1998). Letramento: um tema em três gêneros, Belo Horizonte: Autêntica.

SOARES, M. (2004). Letramento e Alfabetização: as muitas facetas. Revista Brasileira de Educação, 25, 5-17. https:// doi.org/10.1590/S1413-24782004000100002

STROUPE, D. (2014). Examining Classroom Science Practice Communities: How Teachers and Students Negotiate Epistemic Agency and Learn Science-as-Practice. Science Education, 98(3), 487-516. https://doi.org/10.1002/sce.21112

TEIXEIRA, P. P., OLIVEIRA, R. D. V. L. de, QUEIROZ, G. R. P. C. (2019). Uma introdução aos conteúdos cordiais: pensar as Ciências com a razão do coração. In P. P. TEIXEIRA, R. D. V. L. de OLIVEIRA, \& G. R. P. C. QUEIROZ (Org.). Conteúdos Cordiais. Biologia Humanizada para uma Escola sem Mordaça. (ix-xxix). São Paulo: Livraria da Física.

VALLADARES, L. (2021). Scientific Literacy and Social Transformation. Science EंEducation, 30, 557-587. https:// doi.org/10.1007/s11191-021-00205-2

VIEIRA, N. (2007). Literacia Científica e Educação de Ciência: dois objectivos para a mesma aula. Revista Lusófona de Educą̧ão, 10, 97-108.

VOGT, C. (2006). Ciência, comunicação e cultura científica. In: C. Vogt (org.). Cultura científica: Desafios. São Paulo: Edusp; Fapesp. p. 18-26.

WENGER, E. (2016). Communities of practice: learning, meaning and identity. Cambridge University Press.

YORE, L. (2012). Science literacy for all: more than a slogan, logo, or rally flag! In K, Tan \& M. Kim (Eds.). Issues and challenges in science education research (pp. 5-23). Netherlands: Springer Netherlands.

\section{NOTAS}

1 Em itálico deixaremos os enunciados tal como encontrados em Sasseron \& Carvalho (2008). Em caracteres normais encontram-se descrições e/ou comentários nossos. 


\section{Maíra Batistoni e Silva}

Doutora em Educação. Professora Doutora do Departamento de Fisiologia do Instituto de Biociências da Universidade de São Paulo (IBUSP). Coordenadora do LaPPEC (Laboratório de Pesquisa em Práticas Epistêmicas e Científicas no Ensino de Ciências) IBUSP.

Universidade de São Paulo, Instituto de Biociências, São Paulo, SP - Brasil.

E-mail: mbatistoni@usp.br

\section{Lúcia Helena Sasseron}

Livre docente em Educação. Professora Associada do Departamento de Metodologia de Ensino e Educação Comparada da Faculdade de Educação da Universidade de São Paulo (EDM-FEUSP). Coordenadora do LaPEF (Laboratório de Pesquisa e Ensino de Física) FEUSP.

Universidade de São Paulo, Faculdade de Educação, São Paulo, SP - Brasil.

E-mail: sasseron@usp.br

\section{Contato:}

Departamento de Fisiologia Instituto de Biociências da Universidade de São Paulo - USP Rua do Matão, travessa 14, nº 101 Cidade Universitária - São Paulo - SP | Brasil

CEP 05.508-090

\section{Editor responsável:}

Vanessa Cappelle

Centro de Ensino de Ciências e Matemática de Minas Gerais - CECIMIG

Faculdade de Educação - Universidade Federal de Minas Gerais revistaepec@gmail.com 